\title{
Development Process and Review of the International Trade Theory
}

\author{
Zhou Meini \\ dept. Chongqing University of Science and Technology \\ School of Business Administration \\ Chongqing, China \\ E-mail: Zhoumeini@yahoo.com.cn
}

\begin{abstract}
The international trade theory experienced several periods of development from Classical to Neoclassical, to New Trade Theory, then to New Classical Trade Theory. The Classical, Neoclassical and the New Trade Theory all provide a explanatory power for the birth of international trade. While the New Classical Trade Theory offers a uniform theoretical core for internal and international trade, of which the perfect theoretical frame and powerful realistic explanation are extremely remarkable, which provides a new angle and point of view for the study over international trade.
\end{abstract}

Keywords- international trade theory; development; review

\section{INTRODUCTION}

The international trade theory experienced several periods of development from Classical to Neoclassical, New Trade Theory, and then the New Classical Trade Theory. The earliest over international trade had its birth in the end of 15th century and initial period of 16th century. That is, during the period of western countries' primitive accumulation of capital and the main theory is mercantilism. It is claimed of the theory that the only form of wealth is the metal---gold and silver. People can gain them though exchange and for a nation, it is to increase the social wealth. Hereby, the way to gain gold and silver is international trade.

\section{Classical INTERNATIONAL TRADE THEORY}

In the late 1790s, the point of mercantilism was challenged by the classical economists. Based on criticizing the mercantilism, Adam Smith proposed the division of labor theory. It has been 41 years from Adam Smith proposed the absolute cost in his the Wealth of Nations in 1976 to David Ricardo proposed the comparative cost in his the Principles of Political Economy and Taxation in 1817. This is the foundation period of international trade theory, that is, the Classical period.

The absolute cost of Adam Smith is based on the division of labor theory. Adam introduced the division of labor theory to the field of international trade and established his absolute cost theory, thus demonstrating the fact that a nation can make the sources of each country most efficiently used to gain the increase of the total production, the enhance of consumption level and the save of labor time as long as the nation specially produce the products of which its production cost is lower than any other country in order to exchange the products of which the cost is high than any other country with its cost-low products. Adam pointed out that the base of international trade lies in the difference of the absolute cost among the products of all countries. This absolute cost difference derives from:

1) nature endowments difference (nature endowment is one of the sources of absolute cost advantage);

2) acquired difference (special techniques or crafts acquired after training or education).

The absolute cost theory is quite significant since it for the first time demonstrates the trade mutually-beneficial rationale, overcomes the one-sided point of mercantilism that international is only beneficial to one side. This run-run theory is still valuable nowadays for opening wider to the world, actively participating in the international productionsharing trade.

The British classical economist David Ricardo proposed the international trade theory of comparative interest based on Adam's absolute interest. David's theory is established with the premise of the assumption that only one production element is needed in production---labor force. David points out that the base of international trade lies in the price difference brought by the labor productivity difference (technical difference) when all the countries are producing the same product. When two kinds of products are produced, the labor productivity will further be the comparative technical difference when the countries produce different products. The reason or motivation of international trade is the price difference in the commodity and the producers' pursuit of high price. And the structure of international production-sharing is that every country specially produce the products with their comparative advantage and further do exchange according to their need while the result of international trade is that each country can increase their real income level through international trade.

The birth of Ricardo's comparative cost theory means the establishment of international trade theory system. Applying the abstract method, Ricardo made a series of premise assumptions over the theory's application. Since great difference exists between the premises of these assumptions and the real economic society, thus dramatically influencing the explanatory power of the theory. However, the construction of the theory model aims to prove the universality of the production-sharing and mutual-benefit of international trade and not to concretely plan for the international production-sharing pattern. A long time after 
that, the development of the study over international trade theory are all carried out based on approaching the reality by loosening or changing the assumption conditions of the theory.

However, a further study over the theory proves that Ricardo's Model can always be established under the premise that only one production factor---labor force and unchanging returns to scale. But examples to prove the inability of the theory can also be found as long as there are more than two products. Meanwhile, the theory is established with the assumption of only one production factor (labor force) which makes it hard to explain the comparative advantage under the situation of multi-factors existing.

\section{NEOClASSICAL INTERNATIONAL TRADE THEORY}

In the 1930s, Swedish economist Ohlin published Interregional and International Trade, in which he put forward Factor Endowment Theory that replaces Ricardo's Single Production Element Theory with a variety of factors theory in interdependent structure of production. Ohlin's Factor Endowment Theory is called Neo- classical International Trade Theory, and his model is called $\mathrm{H}-\mathrm{O}$ model.

Heckscher and Ohlin think, in realistic production, what put in is not only labor, but also other factors. What's more, putting in two factors is a basic condition of production process. According to Factor Endowment Theory, if two countries produce the same product at the same level of technical skills, then price difference comes from cost difference; with the latter itself comes from the price difference of factors in the process of production. While price difference of factors depends on the country's comparative abundance degree, namely it is endowment differences. Different products require different proportions of the two factors, so when a production-intensive country produces a product that using its abundant factors, the cost is comparatively low; otherwise, it is comparatively high. As a result, price advantage comes into being because various countries produce and change the same products; the practice promotes the appearance of international trade and division of labor. This is the narrow definition of Factor Endowment Theory.

While in a broader sense, Factor Endowment Theory points out, if the involved countries share same market price, same price of factors of production, and same technical skill, then the international trade depends on each country's endowment of factors of production. The structure of production shows that every country specializes in producing the products which it has comparative endowment advantage. Factor Endowment Theory hypothesizes that, when factors transfer between different departments, opportunity cost that increases production remains the same.

The Factor Endowment Theory of the Neoclassical International Trade Theory seeks the reasons why international trade come into being from different structural factor endowment and different comparative prices between countries caused by it, thus overcomes the limitation of Ricardo's model of the hypothesis of one factor, which is a considerable success. However, in $\mathrm{H}-\mathrm{O}$ model, as far as absolute figure is concerned, the resource endowment of a certain factor that one country owns may surpass another country with the premise excluding the possibility of return of scale, so it concerns only the comparative amount of resource endowment. If a country belongs to a laborabundant country, and compared with other countries its preference type lies in labor-intensive product, then the wage rate is higher when it is in a closed environment. Therefore, $\mathrm{H}-\mathrm{O}$ model hypothesizes that both countries have the same preference. However, even this hypothesis exists, there are still some limitations in $\mathrm{H}-\mathrm{O}$ model, namely the so called factor intensity reversal, which hypothesizes that laborintensive products in one country turns out to be produced with capital-intensive technology. If there is factor intensity reversal, $\mathrm{H}-\mathrm{O}$ theory can no longer hold water.

\section{NEW TRADE THEORY}

After H-O model, the driving force of the development of trade theory comes from the development of data collection and processing technology, as well as the possibility of provided empirical test on trade theory. "Leontief paradox" arises some doubts for the general applicability of $\mathrm{H}-\mathrm{O}$ model, and provides an opportunity for the advance of international trade theories. By improving $\mathrm{H}-\mathrm{O}$ model, some researchers introduce such factors of production as human capital and land, and think over the difference of factor endowments between countries on a broader basis, which has gotten some results. Others try to create the new trade theory by abandoning some important assumption of H-O model.

Based on product content, there are two basic types of international trade. One is inter-industry trade, which means one country imports and exports the commodities produced by different industrial sector, the other is intra-industry trade which shows that one country not only imports but also exports the manufactured goods of the same category, and two countries import and export the goods above from each other. As for the new trade phenomenon in this sector, it is hard to give a convincing explanation for analyzing the traditional trade theories of inter-industry trade. Paul Krugman and other economists take the reasonable elements of traditional trade theories, build a new analysis framework and put forward the New Trade Theory. These economists use industrial organization theory and the theory of market structure to explain the new phenomenon of international trade, and also use imperfect competition, increasing returns to scale, product differentiation and other concepts and ideas to build the new trade theory model and analyze the basis of intra-industry trade, which comes to a series of new conclusions.

Neoclassical Trade Theory holds that the reason why trade occurs is that the relative factor endowment differences between two countries is the root cause of the occurrence of international trade. New Trade Theory claims that the basic 
cause of trade occurrence is due to the existence of economies of scale, relative factor endowment differences, and the degree of scale economy and monopoly power. Even if there are no relative factor endowment differences between two countries, the trade is likely to happen because of scale economy and monopoly.

Regarding the business model of trade, Neoclassical Trade Theory draws a conclusion from $2 \times 2 \times 2$ model: the countries with rich labor force export labor intensive products, and import capital intensive products. However, New Trade Theory believes that when scale economy and imperfect competition are introduced and the limitation of $2 \times 2 \times 2$ model disappears, the following results will be achieved:

1) the existence of different products leads to the intraindustry trade.

2) because of the existence of scale economy and monopoly, different countries have different condition of using scale economy and different reasons of the existence of monopoly, which will result in the price difference of commodities. The pattern of merchandise trade is that the country with low cost becomes the net exporter of this commodity; the discrimination of relative prices leads to two-way trade.

3) after introducing several kinds of commodities and elements, the two countries have some uncertainties in commodity production and trade, that is to say, there are several equilibrium points of production and trade.

As for benefits of trade, the traditional trade theory holds that if trading countries develop comparative advantages, they will get benefits. Free trade is the best choice of trade. New Trade Theory points out that under the market structure of scale economy and imperfect competition, the economy run in a next-best condition, and for one country, the trade may lead its benefits to drop. Therefore, free trade policy may not be the best policy, which has also been the basis for all countries to perform strategic trade policy.

In the early period of New Trade Theory system, there are many other hypotheses and theories to explain the cause of international trade. For example, Availability Theory of Kravis(1956), Technological Gap Theory of Posner(1961), Product Life Cycle Theory of Hirsch(1967) and Vernon(1966), and Theory of Demand Preference Similarity of Linda(1961)etc.

Besides, there are other explanations of intra-industry trade in the early period:

1) the explanation of transportation cost.

2) intermittent trade of Grubel(1967) and Lloyd(1975);

3) import and export from storage and distribution(transit trade) or re-export trade through simple processing without changing its nature (package, subpackage, purification etc.).

4) lower taxation caused by government prevention leads to transit trade;
5) intra-sector trade which is fully similar and belongs to the same SITC but is considered to be different by the consumers;

6) the New H-O Theory of Falvey(1981), which aims to explain the international trade in vertical differentiated products of the same type(difference of high and low quality).

7) Neo-Chamberlin Model. This model is used to explain the horizontal differentiation of products (same quality but different features which come from real or hypothetical differences) and the occurrence of intraindustry trade in the condition of the decline of average production cost.

Compared with the traditional trade theory, the hypotheses of New Trade Theory are more realistic, especially; it gives a better explanation of intra-industry trade. It doesn't totally repudiate the traditional theory, and its main ideas and analysis methods is not beyond the category of advantages and disadvantages. The difference between New Trade Theory and the traditional trade theory lies in the different trade pattern they study and different theoretical forms. The conflict of hypotheses is the root of different conclusions about the explanation of trade phenomenon.

\section{New Classical International Trade Theory}

Before the new classical economics, the theory analysis framework of economy about consumers and makers is absolutely apart. And Mr. Yang Xiaokai, a Chinese economist, turned the study object of economy from a given organization structure under the optimal resource allocation problem to technical and economic organization of the interaction and evolution research, founded the new classical economics from the discussion of labor division of Smith in the absence of pure consumers and manufacturers had absolute separation condition. Its theoretical research tool--the inframarginal analysis is much newer than the neoclassical economics, while in the thought origin it is much more ancient than the neoclassic economics. Yang Xiaokai and others in new classical framework of international trade study, called the New Classical Trade Theory, also called the Theory of Endogenous Trade.

The New Classical Trade Theory is adopted to study the personal choice of the professional level of the decisions about the level of division of labor evolution to explain the development of the trade. Yang Xiaokai established an endogenous division of labor and specialization trade model, the research shows that: with the transaction efficiency of continuous improvement, increase the level of division of labor. While the economic development, trade and market structure change phenomena are different aspects of the process of division of labor evolution. Equilibrium structure of division of labor also from individuals provide for oneself (it is not necessary for both of domestic and international trade) jumps to partial division of labor (appears at the local market, trade does not exist between the local market and the 
local market scale is smaller than the population size of a country, there is no unified domestic market), and then jumps to a larger part of the division of labor (it appears because of the high level of division of labor, there is no international trade), to the development of a greater part of division of labor(a number of countries form a united market, international trade, but the markets are divided between), finally to complete division of labor(the whole world formed the unified international market). Trade in the transaction efficiency improvement is produced in the process of the development of domestic trade to and from the international trade.

Yang Xiaokai has also established a both endogenous comparative advantage and comparative advantage New Classical model(Sachs, Yang, and Zhang, 1999a,b), their study shows: along with the transaction efficiency from very low to very high, balanced international and domestic level of division of labor from two countries provide for oneself completely jumps to two country completely division. During the transformation stage, two element structures may appear. With individuals from all the countries take part in the division of both domestic and international, the dualistic structure will disappear. The transaction efficiency improvement and led to the evolution of division of labor will increase equilibrium aggregate productivity, as well, a state of deterioration of terms of trade and the trade benefits increase may occur at the same time.

The Theory of Endogenous Trade model also includes:

1) DS model (Dixit -Stighlitz, 1977).

DS model displays: the dilemma between economy of scale and diversification of consumption will inside unripe consumption breed class number. Even before the same in all countries, or absence of exogenous comparative advantage conditions can also produce trade benefits, leading to international trade.

2) B-M model (Beeker-Murphy, 1992).

The model uses the dilemma between specialized economy and coordination coasts to endogenous specialization. The research results show: the marginal benefits of division equals the marginal transaction coasts. International trade makes to coordinate this conflict increased space.

3) A compatible endless returns to scale and competitive market extended MSV model (Murphy-ShleiferVishny, 1989).

Their study results show: In the process of promoting industrialization, the terms of trade and population size exists a replaced relation.

The New Classical Trade Theory provides a new viewpoint and perspective for the study of international trade, which makes it become an important school of contemporary international trade theory. Some scholars even think, the New Classical Trade Theory may represent the future of the mainstream of the development of trade theory. At the same time, the theory also provides strong evidence for Smith's trade division theory. The theory of the unique innovation, outstanding performance in:

1) To a certain extent, trade theory is integrated into a unified framework.

The comparative advantage of the traditional trade theory is exogenous comparative advantage, its core is the comparative advantage, New Trade Theory and New Classical Trade Theory of comparative advantage to endogenous comparative advantage, its core is the increasing returns to scale. While the actual economy is often the mixture of the two, has both comparative advantage, and increasing returns to scale. According to the Neoclassical Theory, generally increasing return to scale will make general equilibrium do not exist or is not Pareto optimal. Therefore, the traditional trade theory excludes the possibility to include the New Classical Trade Theory. In the New Classical Trade Theory, Yang Xiaokai (1997) translate the exogenous comparative advantage factor into based on increasing returns to scale of the New Classical Trade model, put the traditional trade theory and New Classical Trade Theory of organic integration. To a certain extent this research integrates existing trade theory into a unified framework.

2) The problems exiting in original trade theory are solved which are in contradiction to the reality.

First of all, according to New Trade Theory, the increasing population will bring higher productivity. The experience of Hong Kong and Japan is consistent, but contrary to India and China before the reform. The New Classical Trade Theory thinks, the transaction efficiency is the determinants of trade development and economic growth, the high rate of population growth on economic growth is related to the market transaction efficiency of a country. In addition, New Trade Theory system does not have an imperfect competition model widely accepted by economy circle, the theory must be in accordance with market structure ,product differentiation an so many other different situation to construct different trade model, leading to the theoretical model of complex, and it is difficult to be united. But in the New Classical Trade Theory, the increasing returns to scale based on specialization are compatible with the competitive market. The trade theory model based on division of labor and specialization avoids the problem of dealing with the structure of the imperfect competition market model to make it universal adaptability.

3) The producer-consumer framework put the development of domestic trade and international trade theory together.

Because the original trade theory assumes that consumer and producer are absolutely separated, domestic trade has got a different principle with international trade, so it can't explain how the trade developed from domestic trade to international trade. While to the New Classical Trade Theory, that exist the conflict of specialized economy and deal spend, the equilibrium level of division labor is determined by the competition of the benefits of division of 
labor and deal spend. Along with the improvement of the transaction efficiency, balanced level of division of labor jumped, and trade spontaneously generated and then developed from domestic trade to international trade during the process of transaction efficiency improvement. The New Classical Trade Theory succeed in explaining how the international trade developed from domestic trade, but put the principle of domestic and international trade together.

4) The compatibility problem of increasing scale rewards and competitive market was solved on a professional basis.

In the Neoclassical Trade Theory, to pursuit of economies of scale will inevitably lead to the weakening of the competition, make increasing scale rewards is incompatible with competitive market, and assuming that the scale rewards is incremental competitive equilibrium cannot coexist with Pareto optimum. But in the New Classical Trade Theory it used specialization as its theoretical basis. During to the constraints of individual labor time, the increasing scale rewards produced by the specialized economy will have a limit. At the same time, under the New Classical Trade frame, everybody is both consumer and producer; demand and supply are the two sides of the market. Consume demand and production supply decided at the same time, the market manipulation of producers offset each other, so maintain the market competition. In the New Classical Trade Theory, the increasing scale rewards based on specialization and the competitive market are inclusive, so it will not lead to a market failure that take advantage of the economy of scale. Manufacturers pursuit of the optimal scale of production under the competition pressure, It is the performance of violent competition. At the same time, the increasing scale rewards is endogenous based on division of labor and specialization in the Neoclassical Trade Theory, it confirms the consistency that exits in balanced competition and Pareto optimum.

However, New Classical Trade Theory also concludes some deficiencies and shortcomings. First of all, the theory model of new classical framework often make some strong assumptions, it limits the practical application of the New Classical Trade model to a certain extent. Secondly, much data on the evolution of division of labor can't obtain from the current statistical information, so it is very hard to use historical data to verify the New Classical Trade Theory, not even economic forecast. Thirdly, the evolution process of division is such slow, as a result, the New Classical Trade Theory has an advantage of explaining the relatively longterm trade phenomenon, it meets people's intuition and observation of domestic trade and international trade of thousand years, but it may lack sufficient explanation for practical economic problems. In view of this, the New Classical Trade Theory is much more theoretical than practical significance.

\section{CONCLUSIONS}

Above all the analysis: the international trade theory experienced several periods of development from Classical to Neoclassical, New Trade Theory to New Classical Trade Theory. The main contributions made by the Classical and Neoclassical Trade Theory are that they disclose the run-run idea of trade mutual-beneficial property, explain the trade phenomenon among the industries. The New Trade Theory contributes a lot to explaining the trade phenomenon within industries. While the New Classical Trade Theory explains the international trade by replacing scale economy with specialization and unifies internal trade and international trade with an internally consistent core, providing a uniform theoretical core for the development of international trade theory. The New Classical Trade Theory helps us clear some contradictions and wrong views brought by the former trade theories, explain a great deal of phenomenon which were not explained before. Its perfect theoretical background and powerful real explanation are remarkable. Meanwhile, it also paves a new way for the study over trade theory.

\section{REFERENCES}

[1] Yang Xiaokai, Zhang Yongsheng New Results of the New Trade Theory, the Comparative Advantage Theory and Empirical Research: the Literature Review [J]. Economics, 2001.2. (In Chinese).

[2] Sachs, Yang Xiaokai, Zhang Dingsheng(1999) Trade Pattern and Economic Development when Endogenous and Exogenous Comparative Advantages Coexist.[D].Harvard Center for International Development Working Paper No.3.

[3] Ji Yun, from Neoclassical to the New Classical: the Latest Developments in International Trade Theory [J]. World Economy. 2000.01, pp83 87 (In Chinese).

[4] Yang Xiaokai. Economics: New Classical Versus Neoclassical Framework [M]. England: Blackwell. 2000. (In Chinese).

[5] Liu Houjun and others International Trade Development-Theory, Policy and Practice [M] Beijing: Science Press, 2003. P8. (In Chinese).

[6] Yang Xiaokai. Speech in E-commerce and Network Decision-Making International Conference [R]. Beijing: 2001.7. (In Chinese). 